\title{
RELATIONSHIP BETWEEN DIABETIC RETINOPATHY AND ITS SEVERITY AND HEALTH- RELATED QUALITY OF LIFE USING NATIONAL EYE INSTITUTE VISUAL FUNCTION QUESTIONNAIRE
}

\author{
Masoud Reza Manaviat ${ }^{1}$, Nasim Namiranian ${ }^{2}$, Mahboube Kermaniann ${ }^{3}$, Elahe Dehestani Ardakani ${ }^{3}$
}

1: M.D. Assistant Professor, Department of Ophthalmology, Shahid Sadughi University of Medical Sciences, Yazd, Iran

2: M.D. Specialist of Community Medicine, Department of Community Medicine, School of Medicine, Shahid Sadoughi University of Medical Sciences, Yazd, Iran

3: Medical Student, School of Medicine, Shahid Sadoughi University of Medical Sciences, Yazd, Iran

TYPE OF ARTICLE: ORIGINAL

\begin{abstract}
Introduction: Diabetic retinopathy (DR) is a serious microvascular complication of diabetes and is one of the leading causes of blindness worldwide. The aim of this study was to assess the impact of DR and its severity on health-related quality of life (HRQOL) in patients with diabetes mellitus in the Diabetic Research Center of Yazd. Methods: In this cross-sectional study, patients with diabetes mellitus who were referred to Diabetic Research Center of Yazd, Iran, between Jan. 2015 and Jan. 2016 were studied. Adult patients with the diagnosis of DR by an expert ophthalmologist were included. HRQOL was measured by the 25 item National Eye Institute Visual Function Questionnaire (NEI-VFQ-25). The severity of DR in eyes was graded into mild, moderate, severe, and proliferative. SPSS version 20 was used via Student t-test analyses to determine the relationship between severity of DR and HRQOL.

Results: Two hundred nine patients ( 76 males/133 females) with an average age of 59.72 years were studied. The frequency of severity of DR was $26.2(\%)$ for mild, $22.8(\%)$ for moderate, $19.4(\%)$ for severe, and $31.6(\%)$ for proliferative. More severe DR was associated with worse HRQOL scores on all of the NEI VFQ-25 subscales $(\mathrm{p}<0.05)$. Individuals with insulin treatment and macular edema showed a modest decline in HRQOL. The domains with the most significant impact were for vision-related daily activities, dependency and mental health: $51.9 \%$ of patients also underwent laser therapy. Descriptive results obtained from the questionnaires quality of life in patients with diabetic retinopathy were scored 0 as the worst and 100 as the best status.

Conclusion: Greater severity of DR was associated with lower general HRQOL and vision-specific HRQOL. Proliferative DR had the most substantial decrease in quality of life compared with those with less severe DR

KEYWORDS: Diabetes mellitus, Diabetic retinopathy, Health-related quality of life, National Eye Institute Visual Function Questionnaire (NEI-VFQ-25)
\end{abstract}

\section{INTRODUCTION}

Diabetes mellitus is a growing problem in the world and has affected almost 150 million people worldwide (1-3). It is expected that more than 200 million people will suffer from this disease by 2025 (3). Almost all diabetic patients as well more than $60 \%$ of the patients with type 2 diabetes suffered from diabetic retinopathy during the first two decades (1). Therefore, it seems that diabetic retinopathy and relevant complications have significant effects on quality of life of diabetic patients. Maximizing quality of life is the most important goal of medical interventions in these patients as well as addressing other chronic diseases. Studies on quality of life of patients can identify the most important measures that should be predicted for increasing that quality of life. These measures ultimately lead to the design of targeted cost-effective interventions (1-2). The results of the present study could highlight the important impact of this problem in diabetic patients along with important relevant aspects of life in order to find useful and

\section{Correspondence:}

Mahboube Kermanian, School of Medicine, Shahid Sadoughi University of Medical Sciences, Yazd, Iran.

Tel: +98.9134500148, Email: mah.kermanian@yahoo.com

Received: January 13, 2016, Accepted: March 15, 2016, Published: June 2016

iThenticate screening: January 17, 2016, English editing: March 21, 2016, Quality control: March 23, 2016

(c) 2016 The Authors. This is an open access article under the terms of the Creative Commons Attribution-NonCommercialNoDerivs License, which permits use and distribution in any medium, provided the original work is properly cited, the use is non-commercial and no modifications or adaptations are made. 
effective intervention programs with better understanding of patients' problems and concerns. The present study aimed to assess the relationship between diabetic retinopathy and its severity and health-related quality of life using National Eye Institute Visual Function Questionnaire.

\section{MATERIAL AND METHODS}

\subsection{Research design and setting}

This is a cross-sectional study on diabetic retinopathy patients who visited Yazd Diabetes Clinic, Yazd, Iran between Jan. 2015 and Jan. 2016.

\subsection{Sampling}

The sample size was calculated as 200 individuals based on the formula for estimation of a ratio considering $5 \%$ significance level and $80 \%$ power of test according to previous similar studies (3). The final sample size was determined as 220 individuals by taking into account missing data. First, the participants were selected using a convenience sampling method among eligible individuals by observing inclusion and exclusion criteria (based on a diagnosis from an ophthalmologist). Specific codes were assigned to the patients.

\subsection{Selection criteria}

Patients with diabetes, authoritative diabetic retinopathy diagnosed by an optometrist, and ages of 40 to 80 were included. Patients with a diagnosis of nondiabetic retinopathy were excluded from the study.

\subsection{Data collection}

Individuals were selected from patients with diabetic retinopathy who visited Yazd Diabetes Clinic. Information on diabetic cases was collected from the patients' records in the clinic. In the case of incomplete information, additional steps were performed through interviews with patients and ophthalmologists. A vision-related quality of life questionnaire (NEI-VFQ39) was distributed among the patients. The registration form included: a) general information and demographic form; the required data were collected using a self-administered questionnaire; the required information included age, gender, course of diabetes, the severity of retinopathy, and the number of laser therapy and injection of Avastin. b) The quality of life questionnaire in the patients with diabetic retinopathy: Information on quality of life was collected using a questionnaire, which consisted of 25 items (NEI-VFQ39). The questionnaire was translated by Soheila Asgari et al. in Iran. The authors also assessed and confirmed the reliability and validity of the scale.

\subsection{Research ethics}

A brief explanation on the questionnaire and the project was given to the patients. Due to the specific arrangement of the questionnaire items as well as literal and visual problems of the patients, the questions were read by the interviewer, and the responses were recorded in the questionnaires by the interviewer.

\subsection{Statistical analyses}

The collected data were entered into SPSS Statistics for Windows (IBM Corp. Released 2011, Version 20.0, Armonk, NY). According to the major guidelines, 12 subscales were included in the questionnaire. The collected data were described in tables, graphs, mean, median, and standard deviation. Data analysis was performed using Student t-test.

\section{RESULTS}

In total, 209 diabetic patients were eligible for the study, among which 76 patients were males (36.4\%) and 133 patients were females (63.6\%). Only $2.4 \%$ of the patients suffered from diabetes type I, and $97.6 \%$ of the patients suffered from diabetes type II. In addition, $64.6 \%$ of the patients were treated with insulin, and the remaining patients were given oral medications. In total, 55 patients $(26.2 \%)$ suffered from mild retinopathy, 48 patients (22.8\%) suffered from moderate retinopathy, 41 patients (19.4\%) suffered from severe retinopathy, and 68 patients (31.6\%) suffered from proliferative retinopathy patients. Moreover, $21.2 \%$ of the patients were diagnosed with macular edema, while 165 participants did not show any signs of macular edema. Only $1 \%$ of the patients underwent vitrectomy. Furthermore, $18.3 \%$ of the patients were injected with Avastin. Minimum age of the participants was 40 years old; maximum age of the participants was 78 years old (mean age $=59.72 \pm 9.2$ ). A minimum course of diabetes was one year; maximum course of diabetes was 40 years (mean course of diabetes $=15.15 \pm 8.09$ ) (Table 1). In addition, $51.9 \%$ of the patients underwent laser therapy. Table 2 shows the relationship between subscales of the questionnaire and gender of the patients. The contents of Table 1 show a significant difference in subscales of 
general health, social function, and ocular pain in the two genders at significant p-values. General health and ocular pain are higher in women than men, while the social function is higher in men than women. The contents of Table 2 showed that all subscales of quality of life obtained high scores in those patients who took pills for treatment. However, no significant difference was observed in subscales of near vision and distance vision.

Table 1. Relationship between subscales of the questionnaire and gender of the patients

\begin{tabular}{|l|l|l|l|l|}
\hline Dimensions $($ mean \pm SD) & Women $(\mathrm{n}=133)$ & Men $(\mathrm{n}=76)$ & $p$-value & Total \\
\hline General health & $32.56 \pm 9.19$ & $24.96 \pm 10.23$ & 00.00 & $27.66 \pm 10.5$ \\
\hline General vision & $30.74 \pm 9.46$ & $31.02 \pm 9.49$ & 0.841 & $30.92 \pm 9.46$ \\
\hline Ocular pain & $90.49 \pm 13.27$ & $80.96 \pm 20.06$ & 0.001 & $84.32 \pm 18.87$ \\
\hline Near vision & $64.01 \pm 29.86$ & $69.93 \pm 30.28$ & 0.414 & $67.14 \pm 30.017$ \\
\hline Distance vision & $88.33 \pm 14.04$ & $81.25 \pm 32.46$ & 0.553 & $85.67 \pm 22.09$ \\
\hline Social function & $79.30 \pm 26.29$ & $86.81 \pm 19.36$ & 0.026 & $81.96 \pm 24.27$ \\
\hline Mental health & $70.62 \pm 27.59$ & $73.31 \pm 21.46$ & 0.417 & 71.0725 .59 \\
\hline Role limitations & $74.85 \pm 26.53$ & $74.91 \pm 21.30$ & 0.986 & $74.87 \pm 24.27$ \\
\hline Dependence & $78.91 \pm 31.53$ & $83.64 \pm 22.95$ & 0.261 & $80.6 \pm 28.78$ \\
\hline Driving & $58.33 \pm 28.05$ & $80.37 \pm 22.13$ & 0.067 & $78.57 \pm 23.13$ \\
\hline Color vision & $87.02 \pm 22.74$ & $88.69 \pm 20.85$ & 0.603 & $78.62 \pm 21.98$ \\
\hline Peripheral vision & $73.01 \pm 28.56$ & $74.30 \pm 28.44$ & 0.76 & $73.48 \pm 28.35$ \\
\hline
\end{tabular}

Table 2. Relationship between subscales of the questionnaire and type of treatment for the patients

\begin{tabular}{|l|l|l|l|}
\hline Dimensions (mean \pm SD) & \multicolumn{2}{|l|}{ Studied groups } & $p$-value \\
\cline { 2 - 4 } & Insulin group $(\mathrm{n}=135)$ & Tablet group $(\mathrm{n}=74)$ & \\
\hline General health & $26.62 \pm 11.05$ & $29.54 \pm 9.21$ & 0.047 \\
\hline General vision & $29.27 \pm 9.45$ & $33.91 \pm 8.77$ & 0.001 \\
\hline Ocular pain & $81.82 \pm 19.81$ & $88.90 \pm 16.16$ & 0.007 \\
\hline Near vision & $65.57 \pm 28.67$ & $69.49 \pm 32.31$ & 0.596 \\
\hline Distance vision & $82.73 \pm 17.90$ & $87.96 \pm 25.79$ & 0.755 \\
\hline Social function & $77.59 \pm 25.46$ & $89.40 \pm 20.21$ & 0.001 \\
\hline Mental health & $65.87 \pm 26.89$ & $82.15 \pm 19.20$ & 0.000 \\
\hline Role limitations & $70.21 \pm 24.57$ & $83.53 \pm 22.73$ & 0.000 \\
\hline Dependence & $74.85 \pm 31.09$ & $91.04 \pm 20.27$ & 0.000 \\
\hline Driving & $72.77 \pm 26.97$ & $87.7 \pm 10.52$ & 0.026 \\
\hline Color vision & $84.65 \pm 23.45$ & $93.05 \pm 17.91$ & 0.009 \\
\hline Peripheral vision & $29.95 \pm 69.05$ & $23.79 \pm 81.33$ & 0.006 \\
\hline
\end{tabular}

\section{DISCUSSION}

The results showed that vision-related quality of life is higher in the patients who took pills compared with insulintreated patients. This indicated that quality of life declines as the disease progresses. The quality of life also decreases in the case of insulin treatment. In the present study, a subscale of social function was higher in men than in women. This can be justified by taking into account basic conditions of the two genders in society. This is because men benefit more from higher working conditions and social presence than women. In a similar circumstance, quality of life decreased in the case of macular edema, laser therapy, and Avastin injection. These issues place emphasis on reduced the quality of life in patients with advanced disease. Various studies were conducted on the vision-related quality of life in the patients with diabetic retinopathy (1-8). Coynec et al. (2004) showed that loss of independence and mobility associated with decreased visual function and visual loss were major concerns. Moderate, severe NPDR (non-proliferative diabetic retinopathy) and proliferative DR associated with visual impairment have a significant impact on quality of life, particularly in the areas of independence, mobility, leisure, and self-care activities (3). These results are consistent with the results of our study, which indicated that quality of life declined as the severity of retinopathy increased. Another study in collaboration with two teaching hospitals was performed in this context in Athens and London in 2011(6). In the former study, the results showed that the patients with diabetic retinopathy and macular edema had a lower quality of life than the general population. Therefore, prevention and management of diabetic retinopathy and macular edema are crucial for the improved quality of life in these patients. These results were highlighted in the current study and other similar studies (4 and 8 12). Keshif Mazhar et al. (2011) showed that greater severity of diabetic retinopathy was associated with lower 
general and vision-specific quality of life in the patients with diabetic retinopathy (5-13). This finding is consistent with the results of the present study. Fenwick et al. (2012) studied 577 patients using a questionnaire (EQ-5D). They showed that severity of retinopathy and macular edema and vision loss are not associated with changes in quality of life (6). Then, the author wrote that these findings suggest that the EQ-5D, i.e. the questionnaire, lacks sensitivity in assessing the impact of the severity of retinopathy and macular edema on parameters of quality of life. In addition, the results of the former study cannot be compared with the results of the present study due to the different types of questionnaires used in the two studies. In fact, such comparisons are not reliable. Brown et al. (2002) assessed and compared the impact of retinopathy and macular edema on the quality of life. The authors showed that similar levels of visual acuity loss associated with diabetic retinopathy and macular edema caused a similar reduction in quality of life. This issue was not assessed in the present study, which can be considered in future studies. Various studies were performed in conjunction with type I diabetes and vision-related quality of life (12-15). Many studies have assessed the severity of retinopathy and macular edema and their impacts on quality of life. Limited studies were conducted on patients with type II diabetes. The results of these studies are consistent with those results obtained in the present study. It seems that scholars tend to assess the impact of diabetic retinopathy on quality of life. However, the high prevalence of type II diabetes and therapeutic interventions that have resulted in increased lifetime of diabetic patients emphasizes that the number of people with diabetic retinopathy is increasing. Thereby, it is essential to assess these patients. According to the above-mentioned materials, all studies emphasized reduced quality of life in the patients with diabetic retinopathy. The results of the present study also confirmed this issue.

\section{CONCLUSIONS}

It was not possible to evaluate the effect of therapeutic interventions on quality of life of the patients. In order to evaluate the impact of such therapeutic interventions such as laser therapy and Avastin injection, it is recommended to evaluate the quality of life in the patients with diabetic retinopathy both before and a little after therapeutic intervention. It is also suggested to assess the quality of life in both treated and untreated groups that require therapeutic interventions.

\section{ACKNOWLEDGMENTS:}

We want to thank all who help us to provide this research and publish it.

\section{CONFLICT OF INTEREST:}

There is no conflict of interest to be declared.

\section{AUTHORS' CONTRIBUTIONS:}

All authors contributed to this project and article equally. All authors read and approved the final manuscript.

\section{REFERENCES:}

1) Fong DS, Aiello L, Gardner TW, King GL, Blankenship G, Cavallerano JD, et al. Retinopathy in diabetes. Diabetes care. 2004; 27(suppl 1): s84-s7. doi: 10.2337/diacare.27.10.2540. PMid: 14693935.

2) Soheila A, Hassan H, Saharnaz N, Fotouhi A. Persian version of the 25 -item National Eye Institute Visual Functioning Questionnaire (NEI-VFQ 39): a validation study. Iranian Journal of Ophtalmology. 2011; 23(3): 5-14.

3) Coyne KS, Margolis MK, Kennedy-Martin T, Baker TM, Klein R, Paul MD, et al. The impact of diabetic retinopathy: perspectives from patient focus groups. Family Practice. 2004; 21(4): 447-53. doi: 10.1093/fampra/cmh417. PMid: 15249536.

4) Tadros C, Kontodimopoulos N, Feretis E, Kabanarou S, Peto T. Health related quality of life in patients with diabetic retinopathy. Acta Ophthalmologica. 2011; 89(s248): 1-3. doi: 10.1111/j.17553768.2011.2213.x.

5) Mazhar K, Varma R, Choudhury F, McKean-Cowdin R, Shtir CJ, Azen SP, et al. Severity of diabetic retinopathy and health-related quality of life: the Los Angeles Latino Eye Study. Ophthalmology. 2011; 118(4): 649-55. doi: 10.1016/j.ophtha.2010.08.003. PMid: 21035872. PMCid: PMC3070833

6) Fenwick EK, Xie J, Ratcliffe J, Pesudovs K, Finger RP, Wong TY, et al. The impact of diabetic retinopathy and diabetic macular edema on health-related quality of life in type 1 and type 2 diabetes. Investigative ophthalmology \& visual science. 2012; 53(2): 677-84. doi: 10.1167/iovs.11-8992. PMid: 22205611.

7) Brown MM, Brown GC, Sharma S, Landy J, Bakal J. Quality of life with visual acuity loss from diabetic retinopathy and age-related macular degeneration. Archives of ophthalmology. 2002; 120(4): 481-4. doi: 10.1001/archopht.120.4.481. PMid: 11934322. 
8) Margolis MK, Coyne K, Kennedy-Martin T, Baker T, Schein O, Revicki DA. Vision-specific instruments for the assessment of health-related quality of life and visual functioning. Pharmacoeconomics. 2002; 20(12): 791-812. doi: 10.2165/00019053-200220120-00001. PMid: 12236802.

9) Sharma S, Oliver-Fernandez A, Liu W, Buchholz P, Walt J. The impact of diabetic retinopathy on healthrelated quality of life. Current Opinion in Ophthalmology. 2005; 16(3): 155-9. doi: 10.1097/01.icu.0000161227.21797.3d. PMid: 15870571.

10) Carabellese C, Appollonio I, Rozzini R, Bianchetti A, Frisoni GB, Frattola L, et al. Sensory impairment and quality of life in a community elderly population. Journal of the American Geriatrics Society. 1993; 41(4): 401-7. doi: 10.1111/j.1532-5415.1993.tb06948.x. PMid: 8463527.

11) Hänninen J, Takala J, Keinänen-Kiukaanniemi S. Quality of life in NIDDM patients assessed with the SF20 questionnaire. Diabetes research and clinical practice. 1998; 42(1): 17-27. doi: 10.1016/S01688227(98)00085-0.

12) Klein R, Moss SE, Klein BE, Gutierrez P, Mangione CM. The NEI-VFQ-25 in people with long-term type 1 diabetes mellitus: the Wisconsin Epidemiologic Study of Diabetic Retinopathy. Archives of Ophthalmology. 2001; 119(5): 733-40. doi: 10.1001/archopht.119.5.733. PMid: 11346401.

13) Cusick M, Sangiovanni JP, Chew EY, Csaky KG, Hall-Shimel K, Reed GF, et al. Central visual function and the NEI-VFQ-25 near and distance activities subscale scores in people with type 1 and 2 diabetes. American journal of ophthalmology. 2005; 139(6): 1042-50. doi: 10.1016/j.ajo.2005.01.008. PMid: 15953434.

14) Mangione C, Lee P, Gutierrez P, Spritzer K, Berry S, Hays R. Development of the 25-item National Eye Institute Visual Function Questionnaire. Arch Ophthalmol. 2001; 119(7): 1050-8. doi: 10.1001/archopht.119.7.1050. PMid: 11448327.

15) Varma R, Wu J, Chong K, Azen SP, Hays RD, Group LALES. Impact of severity and bilaterality of visual impairment on health-related quality of life. Ophthalmology. 2006; 113(10): 1846-53. doi: 10.1016/j.ophtha.2006.04.028. PMid: 16889831. 